\title{
Immunoproteomic analysis of outer membrane proteins and extracellular proteins of Actinobacillus pleuropneumoniae JL03
} serotype 3

\author{
Yonghong Liao 2,3, Junhua Deng 3 , Anding Zhang1,2, Mingguang Zhou ${ }^{2}$, \\ Yong $\mathrm{Hu}^{2}$, Huanchun Chen ${ }^{1,2}$ and Meilin Jin*1,2
}

Address: ${ }^{1}$ Unit of Animal Infectious Diseases, National Key Laboratory of Agricultural Microbiology, Huazhong Agricultural University, Hubei, PR China, ${ }^{2}$ College of Veterinary Medicine, Huazhong Agricultural University, Hubei, PR China and ${ }^{3}$ Institute of Animal Science and Veterinary Medicine, Hubei Academy of Agricultural Sciences, Hubei, PR China

Email: Yonghong Liao - ebrain04@163.com; Junhua Deng - dengbetter@gmail.com; Anding Zhang - andye8019@webmail.hzau.edu.cn; Mingguang Zhou - zhoumingguangt@foxmail.com; Yong Hu - huyong1980@126.com; Huanchun Chen - chenhch@mail.hzau.edu.cn; Meilin Jin* - jml8328@126.com

* Corresponding author

Published: 20 August 2009

BMC Microbiology 2009, 9:172 doi:10.1186/1471-2180-9-172

This article is available from: http://www.biomedcentral.com/I47I-2180/9/I72

(c) 2009 Liao et al; licensee BioMed Central Ltd.

This is an Open Access article distributed under the terms of the Creative Commons Attribution License (http://creativecommons.org/licenses/by/2.0), which permits unrestricted use, distribution, and reproduction in any medium, provided the original work is properly cited.
Received: 15 February 2009

Accepted: 20 August 2009

\begin{abstract}
Background: Actinobacillus pleuropneumoniae is the causative agent of porcine contagious pleuropneumonia, a highly contagious respiratory infection in pigs, and all the 15 serotypes are able to cause disease. Current vaccines including subunit vaccines could not provide satisfactory protection against $A$. pleuropneumoniae. In this study, the immunoproteomic approach was applied to the analysis of extracellular and outer membrane proteins of $A$. pleuropneumoniae JL03 serotype 3 for the identification of novel immunogenic proteins for A. pleuropneumoniae.
\end{abstract}

Results: A total of 30 immunogenic proteins were identified from outer membrane and extracellular proteins of JL03 serotype 3, of which 6 were known antigens and 24 were novel immunogenic proteins for $A$. pleuropneumoniae.

Conclusion: These data provide information about novel immunogenic proteins for $A$. pleuropneumoniae serotype 3 , and are expected to aid in development of novel vaccines against $A$. pleuropneumoniae.

\section{Background}

Actinobacillus pleuropneumoniae, a gram negative capsulated rod bacterium, is the etiologic agent of a severe, highly infectious and often fatal pleuropneumonia in swine, which is distributed world wide and results in severe losses in the swine industry. Based on capsular antigens, 15 serotypes of A. pleuropneumoniae to date have been documented, and all serotypes are capable of causing disease though differences in virulence have been described [1]. Among these serotypes, serotype 3 is one of the predominant serotypes in China [2].

So far, satisfactory protection has not been achieved in the A. pleuropneumoniae vaccination field in spite of intensive attempts made on inactivated whole-cell vaccines, live avirulent vaccines, which showed partial protection against challenges with homologous or heterologous serotypes[3]. Although currently available subunit vac- 
cines contain important antigens, such as ApxI, ApxII and ApxIII, produced in various combinations by the different serotypes of A. pleuropneumoniae[4], they could not provide complete protection against A. pleuropneumoniae[3]. Thus identifying more conserved antigens is necessary for the development of novel vaccines, and in this study the immunogenic proteins of JL03 serotype 3 will be investigated to provide data for novel vaccine development. Extracellular proteins (ECPs) and OMPs in pathogens are involved in colonization, adhesion to and invasion of host cells. They interact directly with the host immune systems while playing crucial roles in the course of infections. Thus it is feasible to identify the important vaccine candidates from these sub-fractions. Currently, the immunoproteomic approach is a powerful tool to systematically identify immunogenic proteins from pathogens, and novel antigens have been successfully discovered from $S$. streptococcus [5], B. anthrax [6] and S. flexneri [7] by this approach from bacterial subfractions, such as outer membrane proteins.

Recently, Chung et al. performed systematically proteomic analysis on OMPs of A. pleuropneumoniae serotype 5b, and 47 OMPs were identified[8], and there have been attempts but they are not recent and, therefore, could not use a proteomics approach. And no attempt has been reported so far in analysis of the ECPs of A. pleuropneumonae. The complete genome sequence of A. pleuropneumonia JL03 provided an essential database for applying immunoproteomic approach to JL03. In the present study, we report this approach to JL03 for the first time which involved the identification of immunogenic proteins from its OMPs and ECPs.

\section{Results and Discussion \\ 2-DE profile of the ECPs and OMPs, immunoblotting analysis and identification of immunogenic proteins}

In the present study, linear immobilized $\mathrm{pH}$ gradient strips (310 L IPG $13 \mathrm{~cm}$ ) and 10\% SDS-PAGE gels were used for the prepared samples separation. Figure $1 \mathrm{~A}$ and $1 \mathrm{~B}$ show the 2-DE profile of OMPs and ECPs of A. pleuropneumoniae JL03. The 2-DE and immunoblotting were repeated three times and the results were reproducible. A total of 110 spots and 98 spots were detected on the silverstained gels of OMPs and ECPs respectively by the software ImageMaster v 6.01. After immunoblotting analysis with convalescent sera, 28 immunoreactive spots from OMPs (Figure 1A and 1C) were identified, and they represented 17 proteins. Chung et al. recently identified 47 OM proteins from $A$. pleuropneumoniae $5 \mathrm{~b}$ with an optimized extraction protocol based on the sucrose-density gradient which yielded preparations highly enriched for OM proteins and lipoproteins[8], and 10 of the 47 OM proteins were identified as immunogenic proteins in this study. In addition, Rhonda et al. recently demonstrated the sucrose- density gradient extraction of outer membranes in Campylobacter jejuni produced purer sample than carbonate extraction [9] that was applied in this study. So further study needs to be tried on immunoproteomic analysis of other serotypes of A. pleuropneumoniae with the optimized OMP extraction protocol of Chung et al. for search of more immunogenic OMPs. All the 19 immunoreactive spots from ECPs (Figure $1 \mathrm{~B}$ and $1 \mathrm{D}$ ) that represented 16 proteins were identified whereas no specific immunoreactive protein spot was observed from OMPs and ECPs using control sera. The detailed Peptide Mass Fingerprinting (PMF) results of the immunoreactive proteins are listed in supplemental table S1 [see additional file 1]. Overall, values of gel estimated $p I$ and $M W$ are matched well with their theoretical ones but some discrepancies still exist. Similar migration for several proteins has been observed in proteomic analysis of other pathogens previously $[10,11]$. This might be due to the presence of natural isoforms, posttranslational processing, and/or modification, or an artifact caused by sample preparation.

All identified proteins were predicted by PSORTb 2.0, 10 proteins are annotated as periplasmic proteins, 7 are OMPs, 2 are extracellular proteins, 2 are cytoplasmic proteins, 1 is cytoplasmic membrane protein, and 8 are unknown. The detailed functions of the identified immunoreactive proteins are shown in supplemental table S1 [see additional file 1] according to the results predicted by COGnitor.

Interestingly, 3 immunogenic proteins, MomP1, MomP2 and elongation factor Tu were identified from OMPs and ECPs simultaneously, which might be due to outer membrane vesicles released in the milieu [12], from which outer membrane proteins have been identified successfully from E. coli and A. pleuropneumoniae[8,13], and to dual localization of elongation factor Tu [14].

\section{Characterization of identified immunogenic proteins}

Our immunogenic approach led to the identification of 6 known antigens of A. pleuropneumoniae, namely MomP1, MomP2, ApxIIA, ApxIIIA, Na+-translocating NADH-ubiquinone oxidoreductase subunit A (NqrA) and outer membrane ferric hydroxamate receptor (FhuA) $[15,16]$. And other well-known antigens, like ApxI, ApxIV, outer membrane lipoprotein A (OmlA), outer membrane protein precursor (PalA) and Transferrin binding proteins (Tbp) proteins could not be detected in the present study. ApxIV is only induced in vivo and JL03, serotype 3 strain, can not produce ApxI, and therefore we could not detect ApxI and ApxIV. Tbp proteins are expressed under iron limited conditions and the cells we collected were not prepared under such conditions. So Tbp proteins did not appear in our results. The highly hydrophobic nature of OmlA and PalA might cause their loss during extraction procedure. PalA 

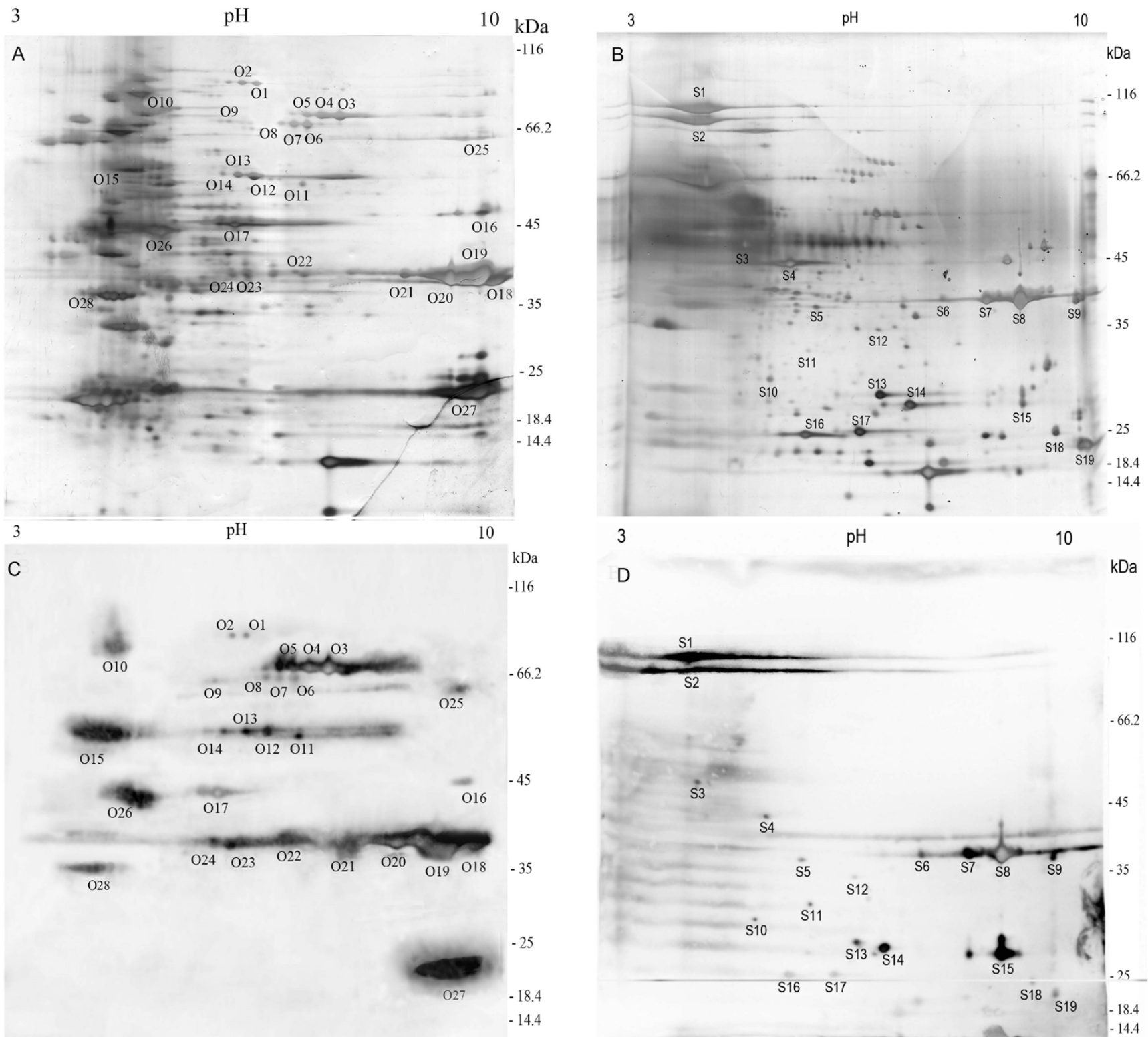

\section{Figure I}

2-DE profile of ECPs and OMPs and immunoblot. 2-DE profile of OMPs (A) and ECPs (B) from A. pleuropneumoniae JL03 strain. Preparative gel stained with Silver Nitrate. Immunoblot of OMPs and ECPs from convalescent sera (C) and (D). The gel spots were encoded using a letter followed by the protein number, which was assigned based on their similar locations on different gels/membranes.

has been proved to be detrimental when used in vaccines[17], and thus we should be cautious about similar immunogenic proteins while applying them to vaccine development.

In addition, we found 16 immunogenic proteins that had an significant sequence similarity to known proteins, and they have already been shown immunogenic in certain pathogenic bacteria, but not in A. pleuropneumoniae before, namely D15/OmpD, LppB, FrdA, MDH, FepA, FrpB, TufB, PotD, GapA, ZnuA, TIG, DegP, TufB, PsaA, FkpA and PTA. The homolog D15/Omp85 is an essential component for outer membrane biogenesis and OMP assembly $[18,19]$. The immunogenicity of D15 and its homolog Omp87 has been demonstrated in Haemophilus ducreyi [20] and Pasteurella multocida [21] respectively. Furthermore, antibodies against the COOH-terminal "surface antigen" domain of D15 are protective against 
Haemophilus influenzae infection in animal models [22]. The immunoreactive spot $\mathrm{O} 16$ was homologous to LppB and shared $49 \%$ sequence identity with LppB of $H$. somni that has been shown as an immunodominant protein [23], and the gene $\operatorname{lp} p B$ of A. pleuropneumoniae is important for survival during infection[24]. Fumarate reductase (FrdA) was found to be involved in biosynthesis of flagella and cell motility, which might contribute to an significantly attenuated A. pleuropneumoniae [25] and loss of the ability in colonizing in the gastric mucosa in Helicobacter pylori[26] after frdA genes were inactivated. Furthermore, Joseph et al. described FrdA as an antigen in Brucella abortus [27]. FepA, FrpB and HbpA are important components in several $A B C$ transport pathways for obtaining iron or regulating iron utilization in vivo or vitro. The immunogenic activity of FepA and FrpB was shown in Klebsiella pneumoniae [28] and Neisseria meningitides [29] respectively, and HbpA was widely conserved and served as an antigen in Leptospira interrogans[30]. Moreover, homologous analysis of these proteins at NCBI revealed a high level identity $(>98 \%)$ with the sequenced serotype 1, 5 and 7 strains respectively. These suggest that they might be new common antigens for $A$. pleuropneumoniae. Highaffinity zinc uptake system protein ZnuA precursor, was essential of $B$. abortus for intracellular survival and virulence in mice[31] and shown immunogenic in Streptococcus suis[5]. PsaA is needed for the adherence of pneumococcal cells and antibodies to PsaA contributed to reduce the nasopharyngeal colonization of challenged pneumococcal cells $[32,33]$. DegPs, a member of the widely conserved HtrA family of serine proteases, were frequently identified as antigens in other pathogens, such as B. abortus [34] and Chlamydia trachomatis [35]. Besides, trigger factor (TIG) has been demonstrated to be an excellent candidate for vaccination against Brucella melitensis [36] and a virulence-related protein in Listeria monocytogenes [37], and similar findings were described about malate dehydrogenase (MDH) of Candida albicans [38] and spermidine/putrescine-binding periplasmic protein (PotD) of Streptococcus pneumoniae [39]. Glyceraldehyde 3-phosphate dehydrogenase (GapA) has been proven to be antigenically conserved proteins, suggesting potential for vaccines in several microorganisms [40]. Homologous protein of translation elongation factor EF-Tu (TufB), a very abundant protein, had been detected in immunological researches of other bacteria, such as C. trachomatis [41] and Shigella flexneri[7]. The periplasm of gram-negative bacteria is well equipped with ATP-independent chaperones and folding catalysts, including peptidyl-prolyl isomerases (FkpA). It is reported recently that FkpA was found to be immunogenic in Bordetella pertussis[42]. Phosphate acetyltransferase (PTA), an enzyme that catalyzes the reversible transfer of the acetyl group from acetyl phosphate to coenzyme A plays a major role in the energy- yielding metabolism[43] and recently has been reported to be immunogenic in S. suis[5].

It is notable that $\mathrm{CbiK}$, IlvG, FepB, AfuC, FatB, GGBP, CysG and Ttg2D, are reported to be immunogenic proteins for the first time in this study whose functions have been biologically demonstrated in some bacteria. Putative periplasmic binding protein $\mathrm{CbiK}$ is involved in the uptake of $\mathrm{Ni}^{2+}$, a cofactor required for urease activity that is important in pathogenesis of pleuropneumonia [44]. The ilv gene of Brucella suis has been identified as a virulence gene[45], and its product, acetohydroxyacid synthase, catalyzes the first common step in the biosynthetic pathway of the branched-amino acids such as leucine, isoleucine, and valine. Iron is essential for bacterial growth, especially for A. pleuropneumoniae in invading and reproducing in porcine respiratory tract where iron is limited. Iron-restriction is an important signal that regulates expression of many genes including some coding for virulence factors [46]. FepB, AfuC and FatB are components of known iron transport pathways, and the immunogenic reactivity of these proteins in this study indicates that these iron-uptake proteins might be potential candidates for development of subunit vaccines. D-Galactose/D-glucose binding protein (GGBP) is a bacterial periplasmic protein, an initial component for both chemotaxis towards galactose and glucose and active transport of the two sugars in Escherichia coli[47]. The crystal structure of uroporphyrinogen-III methylase (CysG) from Thermus thermophilus has been reported[48] and the cysG gene of Salmonella typhimurium is involved in synthesis of both cobalamin (B12) and siroheme[49]. The ttg2D gene encodes a periplasmic component of an ABC-type transport system related to resistance to organic solvents, and Ttg proteins of Pseudomonas putida and N. meningitidis were verified to participate in the uptake of L-glutamate[50].

Novel vaccine candidates need to be highly conserved between strains and so that they induce cross-protection against A. pleuropneumoniae. Recently Goure et al. have identified A. pleuropneumoniae genes that are conserved among all 15 serotypes by comparative genomic hybridization[51]. Of these conserved genes, the genes encoding proteins MomP1 (OMP P5), MomP2 (OMP P5), D15 (OmpD), LppB, PotD, FkbP and FrpB were observed in our results. Besides, NqrA has been demonstrated to be common to all serotypes[15]. Thus these conserved proteins could potentially induce protection against a wide variety of strains and are attractive vaccine candidates.

\section{Conclusion}

In conclusion, the 2DE in combination with Western blot is a specific and powerful method to discover novel antigens from bacterial pathogens. In this study, the identified 
immunogenic proteins from ECPs and OMPs may be significant for the development of new efficient vaccine against A. pleuropneumoniae. The protective efficacy of the identified immunogenic proteins either by alone or in different combinations remains to be evaluated in further studies. The data of this study are expected to aid in development of novel vaccines against $A$. pleuropneumoniae. The present study has focused on 2DE analysis coupled with Western blotting.

\section{Methods}

\section{Bacterial strains and culture conditions}

A. pleuropneumoniae JL03 [52], a Chinese field isolate strain of serotype 3, was used for this study. Bacteria were routinely maintained on tryptic soy agar (Difco Laboratories, Detroit) containing $10 \%$ bovine calf serum and $0.01 \%$ nicotinamide adenine dinucleotide (NAD) and cultured in brain heart infusion (BHI, Difco Laboratories, Detroit) media containing $0.01 \%$ NAD in a rotary incubation shaker running at $180 \mathrm{rev}$ min. For protein extractions, overnight bacterial cultures were diluted 1:100 in 1 $\mathrm{L}$ BHI broth and grown aerobically at $37^{\circ} \mathrm{C}$ at $180 \mathrm{rev}$ min. Three independent cultures at different days were prepared for ECPs and OMPs preparation respectively.

\section{Extracellular proteins sample preparation}

Growth was stopped at the early exponentional phase at an $\mathrm{OD}_{600}$ of $\sim 0.4$. Supernatant containing protease inhibitor cocktail (Roche, Mannheim, Germany) was collected by centrifugation for $10 \mathrm{~min}$ at $7200 \times \mathrm{g}$ (Sigma $3 \mathrm{~K} 12, \mathrm{Nr}$. 12150 ) at $4^{\circ} \mathrm{C}$ and filtered with $0.22 \mu \mathrm{m}$ membrane (Millipore, USA). The supernatant was then treated with $15 \%$ TCA (Sigma Chemical) in ice for $30 \mathrm{~min}$ to precipitate protein. The precipitate was collected by centrifugation at $10000 \times \mathrm{g}$ for $20 \mathrm{~min}$ at $4{ }^{\circ} \mathrm{C}$. Then the precipitated protein was washed three times with ice cold acetone containing $0.1 \%$ DTT to remove traces of TCA, and acetone was finally removed by speed vacuum treatment. Extracellular proteins were solubilized with $7 \mathrm{M}$ urea, $2 \mathrm{M}$ thiourea, $4 \%$ CHAPS, and $65 \mathrm{mM}$ DTT. Protein concentration was determined by the GE Healthcare 2-D Quant Kit (Piscataway, NJ, USA).

\section{OMPs sample Preparation}

OMPs were prepared according to Molloy et al [53], with minor modifications. Briefly, cells were harvested in the middle exponential phase $\left(\mathrm{OD}_{600}, \sim 1.0\right)$ by centrifugation for $10 \mathrm{~min}$ at $7200 \times \mathrm{g}($ Sigma $3 \mathrm{~K} 12, \mathrm{Nr}$. 12150) at $4^{\circ} \mathrm{C}$, and then the pellets were washed twice with cold 50 $\mathrm{mM}$ Tris-EDTA ( $\mathrm{pH}$ 7.5) containing protease inhibitor cocktail (Roche, Germany) and subsequently the cells were suspended in $10 \mathrm{ml} 50 \mathrm{mM}$ Tris-EDTA (pH 7.5) and ruptured by sonication at 50 watts; pulse on, $3 \mathrm{sec}$; pulse off, $3 \mathrm{sec}$. (Sonorex Digital 10 P Sonicator Bandelin, Berlin, Germany), till the value of $\mathrm{OD}_{600}$ decreased to $1 / 10$ of its origin. Unbroken cells and cellular debris were removed by centrifugation at $6000 \times \mathrm{g}$ for $10 \mathrm{~min}$. The supernatant was diluted 10 -fold with ice cold $0.1 \mathrm{M}$ $\mathrm{Na}_{2} \mathrm{CO}_{3}$ (pH 11), and stirred slowly on ice for $1 \mathrm{~h}$. The OMPs were pelleted by ultracentrifugation in a Beckman Optima MAX ultracentrifuge (Palo Alto, CA, USA) at 100 $000 \times \mathrm{g}$ for $1 \mathrm{~h}$ at $4^{\circ} \mathrm{C}$. The supernatant was then discarded, and the pellet was resuspended and washed in 50 mM Tris-EDTA ( $\mathrm{pH}$ 7.5) twice. The pellet was collected by centrifugation at $100000 \times \mathrm{g}$ for $1 \mathrm{~h}$ at $4^{\circ} \mathrm{C}$ and subsequently solubilized in a lysis buffer ( $7 \mathrm{M}$ urea, $2 \mathrm{M}$ thiourea, 4\% CHAPS, $1 \%$ Triton X-100 and $65 \mathrm{mM}$ DTT). Protein concentration was determined by the GE Healthcare 2-D Quant Kit.

\section{Preparation of convalescent sera}

Bacteria JL03 were prepared as described above and the cells were washed once with PBS before dilution. Five pigs free of A. pleuropneumoniae were inoculated intratracheally at dose of $1.0 \times 10^{7} \mathrm{CFU} /$ pig in PBS to prepare the convalescent sera, and three pigs survived. Twenty days after the first infection, the survivors were rechallenged with another identical dose of JL03. Sera were collected a week after the second inoculation and evaluated. Antibody titer of mixed sera from survivors 1:512 was measured by IHA kit (Lanzhou Bioproducts Factory, Lanzhou, China). Sera were collected before inoculation as control sera. All animals were housed and maintained in isolation facilities in accordance with the Animal Care and Use Committee guidelines of Huazhong Agricultural University.

\section{2-DE and immunoblotting analysis}

IEF was performed with the IPGphor II $^{\mathrm{TM}}$ system (GE Healthcare, USA) and the Immobiline DryStrip ${ }^{\mathrm{TM}}$ IPGstrips of $13 \mathrm{~cm}$ (linear $310 \mathrm{pH}$ gradient) according to Gorg et al [54]. The prepared ECPs and OMPs $(150 \mu \mathrm{g} / \mathrm{strip})$ was mixed with rehydration buffer ( $7 \mathrm{M}$ urea, $2 \mathrm{M}$ thiourea, $2 \% \mathrm{w} / \mathrm{v}$ CHAPS, $1 \% \mathrm{w} / \mathrm{v}$ DTT, $0.5 \% \mathrm{v} / \mathrm{v}$ IPG buffer, $0.002 \%$ $\mathrm{w} / \mathrm{v}$ bromophenol blue). The ECPs and OMPs samples were focused for $50 \mathrm{kVh}$ and $75 \mathrm{kVh}$ respectively. After IEF, three gels were run as follows. The IPGstrips were respectively equilibrated for $15 \mathrm{~min}$ with $10 \mathrm{mg} / \mathrm{ml}$ DTT and $40 \mathrm{mg} / \mathrm{ml}$ iodoacetamide in equilibration buffer $(6 \mathrm{M}$ urea, $2 \% \mathrm{w} / \mathrm{v}$ SDS, $30 \% \mathrm{v} / \mathrm{v}$ glycerol, $0.002 \% \mathrm{w} / \mathrm{v}$ bromophenol blue, $50 \mathrm{mM}$ Tris-HCl, $\mathrm{pH}$ 8.8). After equilibration, the second dimension electrophoresis was performed on a $10 \%$ SDS polyacrylamide gel using Hoefer SE600 Ruby (Amersham Biosciences). Proteins of one gel were visualized by staining with silver nitrate (Bio Basic Inc). And gel evaluation and data analysis were carried out using the ImageMaster v 6.01 program (GE Healthcare, USA).

Immunoblot was performed according to Mansfield [55]. Gels were blotted onto PVDF transfer membranes 
(Hybond-P, 0.45 mm; Amersham Biosciences). The membranes were blocked in 5\% BSA in TBS $+0.05 \%(\mathrm{v} / \mathrm{v})$ Tween 20 for $1 \mathrm{~h}$ at room temperature and probed with the convalescent swine sera and control sera (1:1000), for $1 \mathrm{~h}$ at room temperature, and then were washed and incubated with goat anti-porcine IgG $(\mathrm{H}+\mathrm{L})-\mathrm{HRP}(1: 5,000)$ (Southern Biotech, Birmingham, AL, USA) for $1 \mathrm{~h}$ at room temperature, followed by development with Supersignal west pico chemiluminescent substrate (Pierce, Rockford, IL, USA) and imaged on the Image Station $2000 \mathrm{MM}$ (Kodak, Rochester, NY, USA). All experiments were done in triplicate.

\section{In-gel digestion of proteins [5]}

Protein spots of interest were excised from gels and detained with $100 \mu \mathrm{l} 30 \mathrm{mM}$ potassium ferricyanide and $100 \mu \mathrm{l} 100 \mathrm{mM}$ sodium thiosulfate (at a ratio of $1: 1$ ). And the gel pieces were shrunken with $50 \mu$ l acetonitrile and then re-swollen with $5 \mu \mathrm{l}$ of $25 \mathrm{mM}$ ammonium bicarbonate containing $10 \mathrm{ng}$ of trypsin at $4^{\circ} \mathrm{C}$ for $30 \mathrm{~min}$. In-gel tryptic degradation was performed overnight at $37^{\circ} \mathrm{C}$, followed by three subsequent extractions. The pooled extracts were lyophilized and reconstituted in $2 \mu \mathrm{l} 0.1 \%$ TFA v/v prior to MALDI-TOF MS analysis.

\section{MALDI-TOF MS analysis and database searchs}

The sample solution with equivalent matrix solution was applied onto the MALDI-TOF target and prepared for MALDI-TOF-MS analysis according to a previously described procedure [56]. CHCA was used as the matrix. MALDI-TOF spectra were calibrated using trypsin autodigestive peptide signals and matrix ion signals. MALDI analysis was performed by a fuzzy logic feedback control system (Ultraflex $\alpha$ MALDI TOF/TOF system Bruker, Karlsruhe, Germany) equipped with delayed ion extraction. PMF data were searched against the database of JL03 by MASCOT licensed in-house and the NCBInr database using the MASCOT program http://www.matrix science.com.

\section{Bioinformatics tools}

COGnitor http://www.ncbi.nlm.nih.gov/COG/old/xog nitor was applied to sort the identified proteins of $A$. pleuropneumoniae JL03 into functional categories. PSORTb v.2.0 is accessible at http://www.psort.org/psortb/ index.html and applied to predict the subcellular location of the identified proteins.

\section{Authors' contributions}

YL and MJ carried out the molecular genetic studies, participated in the sequence alignment and drafted the manuscript. AZ, JD, YH, YL and $\mathrm{MZ}$ carried out the immunoassays. MZ and JD participated in the sequence alignment. MJ and YL participated in the design of the study and performed the statistical analysis. HC conceived of the study, and participated in its design and coordination. All authors read and approved the final manuscript.

\section{Additional material}

\section{Additional file 1}

Supplementary table S1. List of immunoreactive proteins of OMPs and ECPs

Click here for file

[http://www.biomedcentral.com/content/supplementary/1471-

2180-9-172-S1.doc]

\section{Acknowledgements}

This work was supported by 973 program (2006CB504404), the National Natural Science Foundation of China (30530590), 863 program (2006AA I0A206) and National Key Technology R\&D Program (2006BAD06A II). The work was performed in collaboration with Hubei University. We thank Yanxiu Liu for her suggestions and careful revision of the language of this manuscript.

\section{References}

I. Jacobsen MJ, Nielsen JP, Nielsen R: Comparison of virulence of different Actinobacillus pleuropneumoniae serotypes and biotypes using an aerosol infection model. Vet Microbiol 1996, 49(34): $159-168$.

2. Lu Z, Zhao P, Shao Y, Liu J, Lu B: Study on the inactivated trivalent vaccine against swine infectious pleuropneumoniae: selection of the seed strain, preparation and safety trials of the vaccine. Chinese Journal of Veterinary Science and Technology 2002, 37:33-35.

3. Ramjeet M, Deslandes V, J G, Jacques M: Actinobacillus pleuropneumoniae vaccines: from bacterins to new insights into vaccination strategies. Animal Health Research Reviews 2008, 9(0I):25-45.

4. Frey J, Bosse JT, Chang YF, Cullen JM, Fenwick B, Gerlach GF, Gygi $D$, Haesebrouck F, Inzana TJ, Jansen R, et al.: Actinobacillus pleuropneumoniae RTX-toxins: uniform designation of haemolysins, cytolysins, pleurotoxin and their genes. J Gen Microbiol 1993, 139(8): : 1723-1728.

5. Zhang A, Xie C, Chen $\mathrm{H}$, Jin M: Identification of immunogenic cell wall-associated proteins of Streptococcus suis serotype 2. Proteomics 2008, 8(17):3506-3515.

6. Ariel N, Zvi A, Makarova K, Chitlaru T, Elhanany E, Velan B, Cohen $S$, Friedlander A, Shafferman A: Genome-based bioinformatic selection of chromosomal Bacillus anthracis putative vaccine candidates coupled with proteomic identification of surfaceassociated antigens. Infect Immun 2003, 7 I (8):4563-4579.

7. Ying T, Wang H, Li M, Wang J, Wang J, Shi Z, Feng E, Liu X, Su G, Wei $\mathrm{K}$, et al.: Immunoproteomics of outer membrane proteins and extracellular proteins of Shigella flexneri 2a 2457T. Proteomics 2005, 5( I 8):4777-4793.

8. Chung J, Ng-Thow-Hing C, Budman L, Gibbs B, Nash J, Jacques M, Coulton J: Outer membrane proteome of Actinobacillus pleuropneumoniae : LC-MS/MS analyses validate in silico predictions. Proteomics 2007, 7(II):

9. Hobb RI, Fields JA, Burns CM, Thompson SA: Evaluation of procedures for outer membrane isolation from Campylobacter jejuni. Microbiology 2009, I55(Pt 3):979-988.

10. Molloy MP, Herbert BR, Slade MB, Rabilloud T, Nouwens AS, Williams KL, Gooley AA: Proteomic analysis of the Escherichia coli outer membrane. Eur J Biochem 2000, 267(10):287I-288I.

II. Walz A, Mujer CV, Connolly JP, Alefantis T, Chafin R, Dake C, Whittington J, Kumar SP, Khan AS, DelVecchio VG: Bacillus anthracis secretome time course under host-simulated conditions and identification of immunogenic proteins. Proteome Sci 2007, 5: 11 .

12. Negrete-Abascal E, Garcia RM, Reyes ME, Godinez D, de la Garza M: Membrane vesicles released by Actinobacillus pleuropneumo- 
niae contain proteases and Apx toxins. FEMS Microbiol Lett 2000, I9I(I):109-II3.

13. Lee E, Bang J, Park G, Choi D, Kang J, Kim H, Park K, Lee J, Kim Y, Kwon K: Global proteomic profiling of native outer membrane vesicles derived from Escherichia coli. Proteomics 2007, 7(17):

14. Sanderova H, Hulkova M, Malon P, Kepkova M, Jonak J: Thermostability of multidomain proteins: elongation factors EF-Tu from Escherichia coli and Bacillus stearothermophilus and their chimeric forms. Protein Sci 2004, I3(1):89-99.

15. Cruz W, Nedialkov Y, Thacker B, Mulks M: Molecular characterization of a common 48-kilodalton outer membrane protein of Actinobacillus pleuropneumoniae. Infect Immun 1996, 64(I):83-90.

16. Haesebrouck F, Chiers K, Van Overbeke I, Ducatelle R: Actinobacillus pleuropneumoniae infections in pigs: the role of virulence factors in pathogenesis and protection. Vet Microbiol 1997, 58(24):239-249.

17. Bosch $\mathrm{H}$ van den, Frey J: Interference of outer membrane protein PalA with protective immunity against Actinobacillus pleuropneumoniae infections in vaccinated pigs. Vaccine 2003, 2I(2526):360I-3607.

18. Voulhoux R, Bos MP, Geurtsen J, Mols M, Tommassen J: Role of a highly conserved bacterial protein in outer membrane protein assembly. Science 2003, 299(5604):262-265.

19. Gentle I, Gabriel K, Beech P, Waller R, Lithgow T: The Omp85 family of proteins is essential for outer membrane biogenesis in mitochondria and bacteria. J Cell Biol 2004, I 64(I): I9-24.

20. Burns D, Thomas K, Leduc I, Olsen B, Thomas C, Cameron D, Elkins $\mathrm{C}$ : Cloning, overexpression, purification, and immunobiology of an 85-kilodalton outer membrane protein from Haemophilus ducreyi. Infect Immun 200I, 69(7):4438-4446.

21. Chaudhuri P, Goswami PP: Cloning of 87 kDa outer membrane protein gene of Pasteurella multocida P52. Res Vet Sci 200I, 70(3):255-256.

22. Loosmore S, Yang Y, Coleman D, Shortreed J, England D, Klein M: Outer membrane protein DI5 is conserved among Haemophilus influenzae species and may represent a universal protective antigen against invasive disease. Infect Immun 1997, 65(9):3701.

23. Theisen $M$, Rioux $C R$, Potter AA: Molecular cloning, nucleotide sequence, and characterization of IppB, encoding an antigenic 40-kilodalton lipoprotein of Haemophilus somnus. Infect Immun 1993, 61(5):1793-1798.

24. Sheehan BJ, Bosse JT, Beddek AJ, Rycroft AN, Kroll JS, Langford PR: Identification of Actinobacillus pleuropneumoniae genes important for survival during infection in its natural host. Infect Immun 2003, 7 I(7):3960-3970.

25. Buettner F, Bendallah I, Bosse J, Dreckmann K, Nash J, Langford P, Gerlach G: Analysis of the Actinobacillus pleuropneumoniae ArcA Regulon Identifies Fumarate Reductase as a Determinant of Virulence. Infect Immun 2008, 76(6):2284-2295.

26. Ge Z, Feng Y, Dangler C, Xu S, Taylor N, Fox J: Fumarate reductase is essential for Helicobacter pylori colonization of the mouse stomach. Microb Pathog 2000, 29(5):279-287.

27. Connolly JP, Comerci D, Alefantis TG, Walz A, Quan M, Chafin R, Grewal P, Mujer CV, Ugalde RA, DelVecchio VG: Proteomic analysis of Brucella abortus cell envelope and identification of immunogenic candidate proteins for vaccine development. Proteomics 2006, 6(13):3767-3780.

28. Kurupati P, Teh BK, Kumarasinghe G, Poh CL: Identification of vaccine candidate antigens of an ESBL producing Klebsiella pneumoniae clinical strain by immunoproteome analysis. Proteomics 2006, 6(3):836-844.

29. Ala'Aldeen DA, Davies HA, Borriello SP: Vaccine potential of meningococcal FrpB: studies on surface exposure and functional attributes of common epitopes. Vaccine 1994, I 2(6):535-54I.

30. Sridhar V, Manjulata Devi S, Ahmed N, Sritharan M: Diagnostic potential of an iron-regulated hemin-binding protein HbpA that is widely conserved in Leptospira interrogans. Infection genetics and evolution 2008, 8(6):772-776.

31. Suk K, Watanabe K, Shirahata T, Watarai M: Zinc uptake system (znuA locus) of Brucella abortus is essential for intracellular survival and virulence in mice. Journal of Veterinary Medical Science 2004, 66(9): 1059-1063.
32. Berry A, Paton J: Sequence heterogeneity of PsaA, a 37-kilodalton putative adhesin essential for virulence of Streptococcus pneumoniae. Infect Immun 1996, 64( I 2):5255.

33. Tuomanen E, Briles D, Ades E, Paton J, Sampson J, Carlone G, Huebner R, Virolainen A, Swiatlo E, Hollingshead S: Intranasal immunization of mice with a mixture of the pneumococcal proteins PsaA and PspA is highly protective against nasopharyngeal carriage of Streptococcus pneumoniae. Infect Immun 2000, 68(2):796-800.

34. Tatum FM, Cheville NF, Morfitt D: Cloning, characterization and construction of htrA and htrA-like mutants of Brucella abortus and their survival in BALB/c mice. Microb Pathog 1994, I7(I):23-36.

35. Sanchez-Campillo M, Bini L, Comanducci M, Raggiaschi R, Marzocchi $B$, Pallini $V$, Ratti G: Identification of immunoreactive proteins of Chlamydia trachomatis by Western blot analysis of a twodimensional electrophoresis map with patient sera. Electrophoresis 1999, 20(I I):

36. Yang X, Walters N, Robison A, Trunkle T, Pascual D: Nasal immunization with recombinant Brucella melitensis bp26 and trigger factor with cholera toxin reduces $B$. melitensis colonization. Vaccine 2007, 25(I 2):226I-2268.

37. Bigot A, Botton E, Dubail I, Charbit A: A homolog of Bacillus subtilis trigger factor in Listeria monocytogenes is involved in stress tolerance and bacterial virulence. Appl Environ Microbiol 2006, 72(I 0):6623-663I.

38. Tylicki A, Ziolkowska G, Bolkun A, Siemieniuk M, Czerniecki J, Nowakiewicz A: Comparative study of the activity and kinetic properties of malate dehydrogenase and pyruvate decarboxylase from Candida albicans, Malassezia pachydermatis, and Saccharomyces cerevisiae. Can J Microbiol 2008, 54(9):734-74I.

39. Shah $P$, Swiatlo $E$ : Immunization with polyamine transport protein PotD protects mice against systemic infection with Streptococcus pneumoniae. Infect Immun 2006, 74(10):5888-5892.

40. Perez-Casal J, Prysliak T: Detection of antibodies against the Mycoplasma bovis glyceraldehyde-3-phosphate dehydrogenase protein in beef cattle. Microb Pathog 2007, 43(56): 189-197.

4I. Bini L, Sanchez-Campillo M, Santucci A, Magi B, Marzocchi B, Comanducci M, Christiansen G, Birkelund S, Cevenini R, Vretou E: Mapping of Chlamydia trachomatis proteins by immobiline-polyacrylamide two-dimensional electrophoresis: spot identification by $\mathbf{N}$-terminal sequencing and immunoblotting. Electrophoresis 1996, 17(I): $185-190$

42. Altindis $E$, Tefon BE, Yildirim V, Ozcengiz E, Becher D, Hecker $M$, Ozcengiz G: Immunoproteomic analysis of Bordetella pertussis and identification of new immunogenic proteins. Vaccine 2009, 27(4):542-548.

43. Xu QS, Shin DH, Pufan R, Yokota H, Kim R, Kim SH: Crystal structure of a phosphotransacetylase from Streptococcus pyogenes. Proteins 2004, 55(2):479-48I.

44. Bosse J, Gilmour H, Maclnnes J: Novel genes affecting urease activity in Actinobacillus pleuropneumoniae. J Bacteriol 200I, 183(4): I 242-I 247

45. Boigegrain RA, Liautard JP, Kohler S: Targeting of the virulence factor acetohydroxyacid synthase by sulfonylureas results in inhibition of intramacrophagic multiplication of Brucella suis. Antimicrob Agents Chemother 2005, 49(9):3922-3925.

46. Deslandes V, Nash JH, Harel J, Coulton JW, Jacques M: Transcriptional profiling of Actinobacillus pleuropneumoniae under iron-restricted conditions. BMC Genomics 2007, 8:72

47. D'Auria S, Ausili A, Marabotti A, Varriale A, Scognamiglio V, Staiano $M$, Bertoli $E$, Rossi $M$, Tanfani F: Binding of glucose to the $D$ galactose/D-glucose-binding protein from Escherichia coli restores the native protein secondary structure and thermostability that are lost upon calcium depletion. J Biochem 2006, 139(2):213.

48. Rehse PH, Kitao T, Tahirov TH: Structure of a closed-form uroporphyrinogen-III C-methyltransferase from Thermus thermophilus. Acta Crystallogr D Biol Crystallogr 2005, 61(Pt 7):913-919.

49. Fazzio T, Roth J: Evidence that the CysG protein catalyzes the first reaction specific to B 12 synthesis in Salmonella typhimurium, insertion of cobalt. J Bacteriol 1996, I 78(23):6952-6959.

50. Monaco C, Tala A, Spinosa MR, Progida C, De Nitto E, Gaballo A, Bruni $C B$, Bucci $C$, Alifano $P$ : Identification of a meningococcal 
L-glutamate $A B C$ transporter operon essential for growth in low-sodium environments. Infect Immun 2006, 74(3): I725- 1740.

51. Goure J, Findlay WA, Deslandes V, Bouevitch A, Foote SJ, Maclnnes JI, Coulton JW, Nash JH, Jacques M: Microarray-based comparative genomic profiling of reference strains and selected Canadian field isolates of Actinobacillus pleuropneumoniae. BMC Genomics 2009, 10:88.

52. Xu Z, Zhou Y, Li L, Zhou R, Xiao S, Wan Y, Zhang S, Wang K, Li W: Genome biology of Actinobacillus pleuropneumoniae JL03, an isolate of serotype 3 prevalent in China. PLOS ONE 2008, 3(1):.

53. Molloy MP, Herbert BR, Walsh BJ, Tyler MI, Traini M, Sanchez JC, Hochstrasser DF, Williams KL, Gooley AA: Extraction of membrane proteins by differential solubilization for separation using two-dimensional gel electrophoresis. Electrophoresis 1998, 19(5):837-844.

54. Gorg A, Obermaier C, Boguth G, Harder A, Scheibe B, Wildgruber $\mathrm{R}$, Weiss $\mathrm{W}$ : The current state of two-dimensional electrophoresis with immobilized pH gradients. Electrophoresis 2000 $21(6): 1037-1053$.

55. Mansfield MA: Rapid immunodetection on polyvinylidene fluoride membrane blots without blocking. Anal Biochem 1995, 229(I): I 40-I43.

56. Wyatt MF, Stein BK, Brenton AG: Characterization of various analytes using matrix-assisted laser desorption/ionization time-of-flight mass spectrometry and 2-[(2E)-3-(4-tertbutylphenyl)-2-methylprop-2-enylidene]malononitrile matrix. Anal Chem 2006, 78(1):199-206.

Publish with Bio Med Central and every scientist can read your work free of charge

"BioMed Central will be the most significant development for disseminating the results of biomedical research in our lifetime. "

Sir Paul Nurse, Cancer Research UK

Your research papers will be:

- available free of charge to the entire biomedical community

- peer reviewed and published immediately upon acceptance

- cited in PubMed and archived on PubMed Central

- yours - you keep the copyright 